\title{
СТАТУС ВИТАМИНА D У БЕРЕМЕННЫХ С САХАРНЫМ ДИАБЕТОМ 1 ТИПА
}

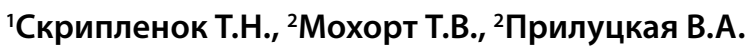

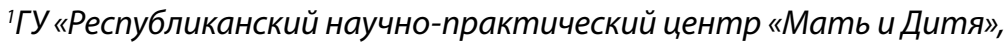 \\ гГУО «Белорусский государственный медичинский университет»
}

ЦЕЛЬ: оценить обеспеченность витамином D женщин с сахарным диабетом 1 типа (CД 1) перед родоразрешением с различной прегравидарной массой тела.

МАТЕРИАЛЫ И МЕТОДЫ: объектом исследования явились беременные с СД 1 (n=77), родоразрешенные в сроке доношенного плода в период с октября по май, которые были разделены на 2 группы в зависимости от прегравидарного индекса массы тела (ИМТ). Группу 1 (Гр 1) составили 38 пациенток с СД 1 и прегравидарным ИМТ<25,0 кг/м², группу 2 (Гр 2) - 39 женщин с ИМТ 225,0 кг/м². Группы исследования были сопоставимы по возрасту, длительности и тяжести СД, уровню НbА1с на протяжении всей беременности. У всех беременных женщин перед родоразрешением осуществлялся забор крови из локтевой вены. Определение уровня 25(OH)D проводилось в сыворотке крови методом иммуноферментного анализа наборами DRG (Германия).

РЕЗУЛЬТАТЫ И ИХ ОБСУЖДЕНИЕ: Установлено снижение уровней 25(OH)D в сыворотке крови У всех обследованных женщин. У беременных с СД 1 в 1-й группе уровень 25(ОН)D составил 33 нмоль/л (26,1-44,1) и был статистически значимо выше (р<0,05), чем у беременных 2 группы - 25,5 нмоль/л (17,4-40,8), что соответствует диапазону дефицита. Выявленное нами более выраженное снижение 25(OH)D у беременных с СД 1 и избыточной массой тела, ожидаемо и соответствует крупным когортным наблюдениям по оценке обеспеченности витамином D лиц с избыточной массой тела.

ВывОДЫ: у беременных с СД 1 в осенне-зимне-весенний период медиана концентрации витамина D находится в диапазоне дефицита не зависимо от прегравидарного ИМТ, но степень недостаточности более выражена у пациенток с прегравидарным ИМТ >25 кг/м². Учитывая потенциальные плейотропные влияния витамина D, своевременная ликвидация его дефицита может быть одним из факторов, который будет способствовать уменьшению тяжести перинатального повреждения ЦНС у новорожденных от мам с СД 1. 